\title{
Assessing Quality of Life of Patients and their Caregivers on Phase I Clinical Trials
}

Gloria Chan (MBBS, MRCP) ${ }^{1}$, Cheng Ean Chee (MD) ${ }^{1}$

1. Department of Hematology-Oncology, National University Cancer Institute, Singapore

\section{Background}

- Patients enrolled in Phase I oncological clinical trials represent a group that are often resilient despite being symptomatic from advanced disease burden and are willing to take chances on treatment.

- Healthcare providers largely focus on objective outcomes such as response and survival, and there is a paucity of data regarding quality of life (QoL) of patients and their caregivers.

- As these patients volunteer to help us in advancing cancer care through their participation, understanding their QoL and financial concerns can help in more effectively targeting their care.

\section{Method}

- Patients and their caregivers seen at the Phase I clinic were invited to participate.

- The table below summarises the instruments administered by a trained personnel at time of initiation of Phase I clinical trial and at 3 time intervals (1 month, 3 months and 6 months)

Paired-sample t-tests were used to test for QoL differences at different time intervals.

\begin{tabular}{l|l}
\hline Instrument & Description \\
\hline $\begin{array}{l}\text { EORTC-core } \\
\text { (QLQ-C30) }\end{array}$ & $\begin{array}{l}30 \text { item questionnaire: } \\
\text { - } 5 \text { functional domains: physical, role, cognitive, emotional and social }\end{array}$ \\
& $\begin{array}{l}\text { - } 3 \text { symptoms scales: fatigue, pain and nausea/vomiting } \\
\text { Single items for symptoms: shortness of breath, loss of appetite, sleep, } \\
\text { constipation, diarrhea and financial impact of disease }\end{array}$ \\
\hline $\begin{array}{l}\text { COmprehensive Score for } \\
\text { financial Toxicity (COST) }\end{array}$ & $\begin{array}{l}11 \text {-item patient-reported out come measure, provides a financial toxicity score } \\
\text { ranging from 0 to 44, lower values indicating greater toxicity. }\end{array}$ \\
\hline $\begin{array}{l}\text { Zarit-Burden Interview } \\
\text { (ZBI) }\end{array}$ & $\begin{array}{l}\text { 22-item questionnaire measuring caregiver's perceived burden of providing family } \\
\text { care } \\
\text { - Includes caregiver's health, psychological well-being, finances, social life, } \\
\text { relationship between caregiver and patient. }\end{array}$
\end{tabular}

- So far, 35 patients have been recruited and 22 of them have completed at least one interval interview at one month.

- Table 1 summarises the patients' demographics

\begin{tabular}{|l|l|c|}
\hline \multicolumn{2}{|l|}{ Patients' characteristics } & N $=35(\%)$ \\
\hline Age (median, range) & $57(42-83)$ \\
\hline Gender & Female & $21(60)$ \\
\hline & Male & $14(40)$ \\
\hline Race & Chinese & $26(74.3)$ \\
\hline & Gastrointestinal & $18(51.4)$ \\
\hline Primary & Gynecological & $9(25.7)$ \\
\hline cancer & Breast & $3(8.6)$ \\
\hline & Lung & $3(8.6)$ \\
\hline $\begin{array}{l}\text { No. of lines of previous treatment } \\
\text { (median, range) }\end{array}$ & $2(5.7)$ \\
\hline \multicolumn{2}{|l}{ Table 1: Patients' characteristics } & $3(0-9)$ \\
\hline
\end{tabular}

\section{QLQ-C30 Outcomes}

- Higher scores for functioning/QoL represent higher levels of functioning or QoL, higher scores for symptoms represents higher level of symptom burden.

- Figure 1 illustrates the QLQ-C30 scores (ranging from 0-100) at baseline and at 1-month interval higher scores represent higher level of functioning and QoL.

\section{Results}

QLQ-C30 Scores at baseline and 1 month

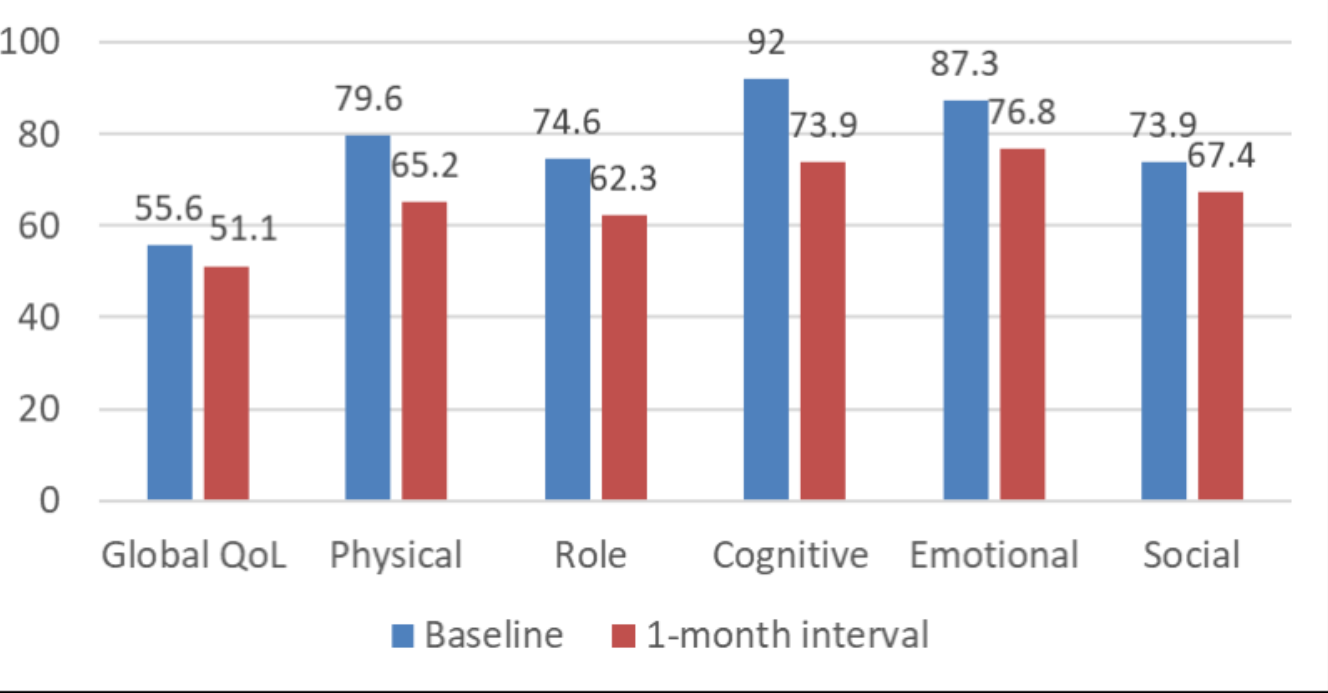

Figure 1: QLQ-C30 scores at baseline and at 1 month interval

- Overall, the mean QoL and functioning levels worsened at the 1 month interval, significantly so for physical, cognitive and emotional functioning scores $(p<.05)$.

- Amongst the symptoms scored, patients were most bothered by fatigue (35.3) and pain (34.1); range 0-100.

- Patients reported significantly more fatigue, nausea, loss of appetite, constipation at the 1 month interval $(\mathrm{p}<.05)$.

- Table 2 summarises the involvement of palliative care for this group of patients symptomatic from their advanced cancer.

\begin{tabular}{|l|c|}
\hline Referral to Palliative Care Services & $\begin{array}{c}\text { No. of Patients } \\
(\%)\end{array}$ \\
\hline Prior to study enrolment & $2(5.7)$ \\
\hline During study & $8(22.9)$ \\
\hline Never referred & $25(71.4)$ \\
\hline
\end{tabular}

Table 2: Palliative care involvement

\section{Financial Toxicities (COST)}

-Financial toxicities graded according to COST scores - Grade 0: 0 to $\leq 21$; Grade 1: 22 to $\leq 40$; Grade 3: $\geq 41$ -Two-thirds of patients on Phase I clinical trials experienced significant level of financial distress (Figure 2).

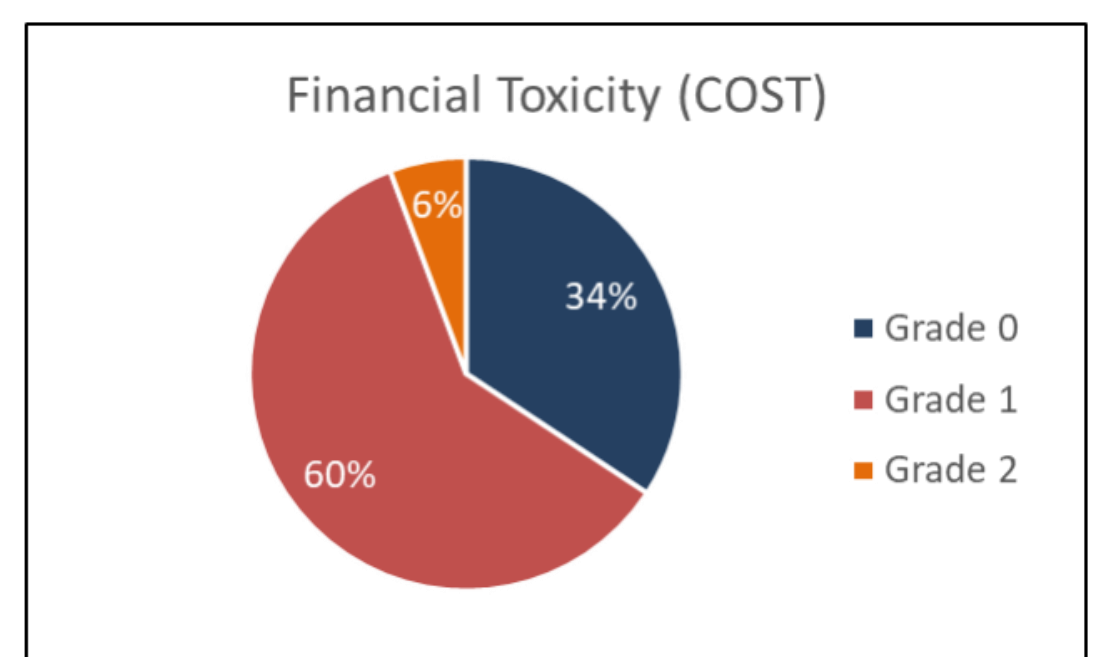

Figure 2: Incidence and Grade of Financial Toxicity

\section{Caregiver Burden (ZBI)}

- 19 primary caregivers of these patients were interviewed (figure 3).

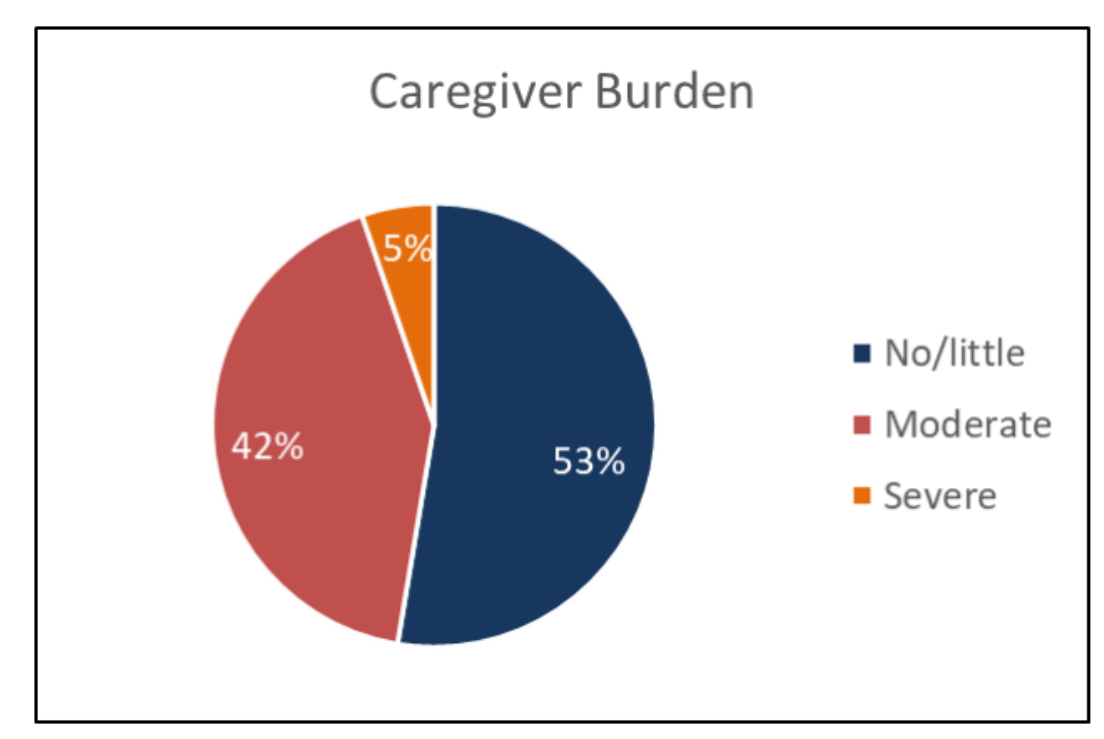

Figure 3: Incidence and Severity of Caregiver burden

\section{Conclusions}

This is the first Asian study reporting QoL of cancer patients and their caregivers in Phase I clinical trials. In this group of heavily pre-treated patients, QoL can significantly worsen. Almost half of caregivers experienced at least moderate levels of caregiver burden. Identifying QoL issues of patients and their caregivers will allow healthcare providers to improve care provided to them.

\section{References}

Aaronson NK, Ahmedzai S, Bergman B, Bullinger M, Cull A, Duez NJ, Filiberti A, Flechtner H, Fleishman SB, de Haes JCJM, Kaasa S, Klee MC, Osoba D, Razavi D, Rofe PB, Schraub S, Sneeuw KCA, Sullivan M, Takeda F. The European Organisation for Research and Treatment of Cancer QLQ-C30: A quality-of-life instrument for use in international clinical trials in oncology. Journal of the National Cancer Institute. 1993; 85: 365-376.

Seng BK, Luo N, Ng WY, et al. Validity and reliability of the Zarit Burden Interview in assessing caregiving burden. Ann Acad Med Singapore. Oct 2010;39(10):758-763.

3. de Souza JA, Yap BJ, Wroblewski K, et al. Measuring financial toxicity as a clinically relevant patient-reported outcome: The validation of the COmprehensive Score for financial Toxicity. Cancer. 2017 123(3):476-484 